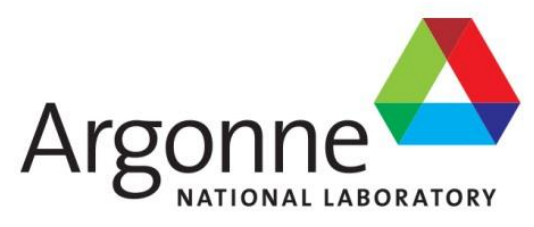

\title{
Update on Activity 6: Target Solution Chemistry Determination of Iron Sulfate
}

Chemical Science and Engineering Division 


\begin{abstract}
About Argonne National Laboratory
Argonne is a U.S. Department of Energy laboratory managed by UChicago Argonne, LLC under contract DE-AC02-06CH11357. The Laboratory's main facility is outside Chicago, at 9700 South Cass Avenue, Argonne, Illinois 60439. For information about Argonne and its pioneering science and technology programs, see www.anl.gov.
\end{abstract}

\title{
DOCUMENT AVAILABILITY
}

Online Access: U.S. Department of Energy (DOE) reports produced after 1991 and a growing number of pre-1991 documents are available free via DOE's SciTech Connect (http://www.osti.gov/scitech/)

Reports not in digital format may be purchased by the public from the National Technical Information Service (NTIS):

U.S. Department of Commerce

National Technical Information Service

5301 Shawnee Rd

Alexandra, VA 22312

www.ntis.gov

Phone: (800) 553-NTIS (6847) or (703) 605-6000

Fax: (703) 605-6900

Email: orders@ntis.gov

Reports not in digital format are available to DOE and DOE contractors from the Office of Scientific and Technical Information (OSTI):

U.S. Department of Energy

Office of Scientific and Technical Information

P.O. Box 62

Oak Ridge, TN 37831-0062

www.osti.gov

Phone: (865) 576-8401

Fax: (865) 576-5728

Email: reports@osti.gov

\section{Disclaimer}

This report was prepared as an account of work sponsored by an agency of the United States Government. Neither the United States Government nor any agency thereof, nor UChicago Argonne, LLC, nor any of their employees or officers, makes any warranty, express or implied, or assumes any legal liability or responsibility for the accuracy, completeness, or usefulness of any information, apparatus, product, or process disclosed, or represents that its use would not infringe privately owned rights. Reference herein to any specific commercial product, process, or service by trade name, trademark, manufacturer, or otherwise, does not necessarily constitute or imply its endorsement, recommendation, or favoring by the United States Government or any agency thereof. The views and opinions of document authors expressed herein do not necessarily state or reflect those of the United States Government or any agency thereof, Argonne National Laboratory, or UChicago Argonne, LLC. 


\section{Update on Activity 6: Target Solution Chemistry Determination of Iron Sulfate}

by

M. Alex Brown, Amanda Youker, George F. Vandegrift

Chemical Science and Engineering Division, Argonne National Laboratory

prepared for

U.S. Department of Energy, National Nuclear Security Administration, Office of Defense Nuclear Nonproliferation

January 31,2014 



\section{CONTENTS}

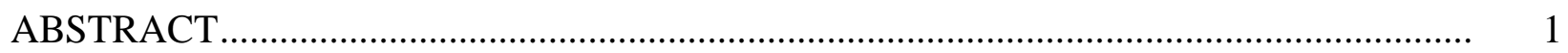

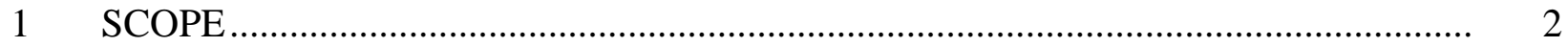

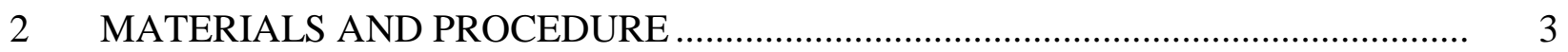

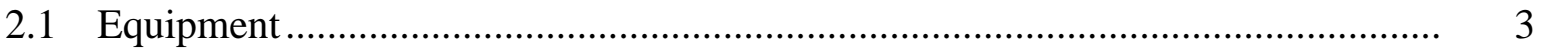

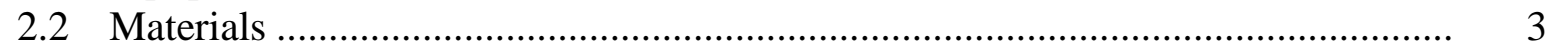

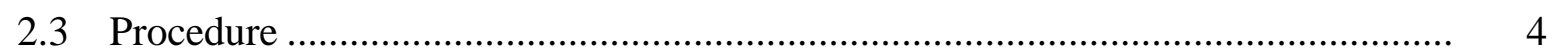

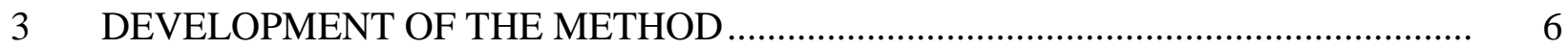

$3.1 \quad$ Peroxide Destruction........................................................................................... 6

3.2 Colorimetry and Method ................................................................................. 6

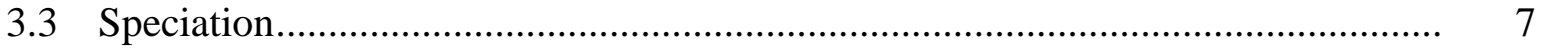

3.4 Calibration Curve ........................................................................................ 8

3.5 Potential Interferences ................................................................................... 9

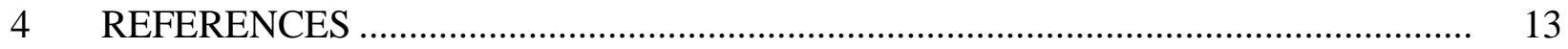

\section{FIGURES}

1 An Extraction of Fe(II)BPhen into Iso-OH from a Sodium Acetate Solution............... 4

2 4,7-Diphenyl-1,10-phenanthroline ............................................................................ 7

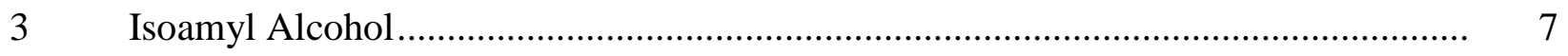

$4 \quad$ Speciation Diagram of Fe(II) and U(VI)-phenanthroline .......................................... 8

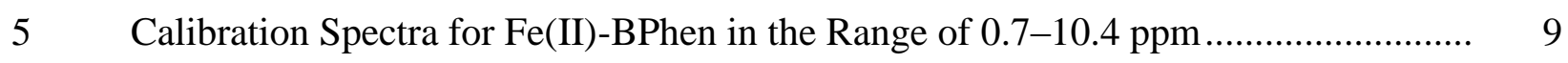

6 The Two-Phase Extraction of Fe(II)-BPhen from a Solution of Uranyl-Sulfate .......... 10

7 The Absorbance of Fe(II)-BPhen in the 0.6 M Uranyl-Sulfate Stock Solution............ 11

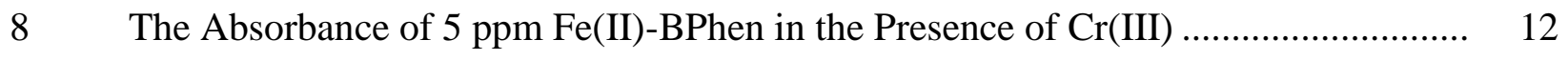

9 The Absorbance of 5 ppm Fe(II)-BPhen in the Presence of a PUREX Raffinate ........ 12 
This page intentionally left blank 


\title{
UPDATE ON ACTIVITY 6: TARGET SOLUTION CHEMISTRY DETERMINATION OF IRON SULFATE
}

\begin{abstract}
Hydrogen peroxide $\left(\mathrm{H}_{2} \mathrm{O}_{2}\right)$ is expected to be generated during the irradiation of Subcritical Hybrid Intense Neutron Emitter (SHINE) solutions due to the radiolysis of water. The anticipated concentrations of $\mathrm{H}_{2} \mathrm{O}_{2}$ could jepordize the solubility of uranium through uranyl-peroxide precipitation. The formation of this insoluble salt has been validated experimentally. SHINE would introduce small quantities (1-10 ppm) of iron(II)-sulfate into target solutions to mitigate the production of peroxide during radiolysis by catalyzing its autodestruction. The method described here quantifies the concentration of iron in the presence of excess uranyl-sulfate and trace amounts of fission and corrosion products as appropriate for irradiated SHINE solutions. Uranyl sulfate and fission products do not interfere with the method. Excess amounts of chromium(III) relative to iron(II) show some interference.
\end{abstract}




\section{SCOPE}

In this task, we are developing a procedure to quantify the concentration of iron in the SHINE target solution. The procedure is necessary to assure that the iron concentration is in the range of $1-10 \mathrm{mg} / \mathrm{L}$, which is required to assure that peroxide autodestruction will be high

enough that uranyl peroxide will not precipitate from the target solution during irradiation. The high concentration of uranium (110,000-150,000 mg/L) compared to the iron concentration makes this analysis challenging. 


\section{MATERIALS AND PROCEDURE}

\subsection{EQUIPMENT}

1. Absorbance spectrometer

a. Wavelength range $400-800 \mathrm{~nm}$

b. Slit width: $1.000 \mathrm{~nm}$

c. Increment: $1.0 \mathrm{~nm}$

2. 2-mL volumetric flask

3. Analytical pipette capable of delivering 100-1000 $\mu \mathrm{L}$

4. Two 1-cm cuvettes with a detectable volume of $0.7-\mathrm{mL}$ solution.

5. Two small test tubes with caps.

\subsection{MATERIALS}

1. Bathophenanthroline (Sigma Aldrich) "BPhen."

a. In a 50-mL volumetric flask, weigh $\sim 16 \mathrm{mg}$ and dissolve in $30 \mathrm{~mL}$ of pure ethanol. Fill to 50-mL mark with deionized (DI) water.

2. Isoamyl alcohol (Sigma Aldrich) "Iso-OH."

3. Hydroxylamine (Sigma Aldrich, Trace Metals).

a. Prepare $5 \mathrm{~g}$ in $50 \mathrm{~g}$ of DI water in a separation funnel.

b. Add $3 \mathrm{~mL}$ of BPhen.

c. Add $3 \mathrm{~mL}$ of Iso-OH.

d. Shake vigorously for 1 minute and allow the phases to separate.

e. Drain the lower phase containing the purified hydroxylamine.

4. Sodium Acetate (Sigma Aldrich, Trace Metals).

a. Prepare $5 \mathrm{~g}$ in $50 \mathrm{~g}$ of DI water in a separation funnel.

b. Adjust the $\mathrm{pH}$ to 9 using ammonium hydroxide.

c. Add $3 \mathrm{~mL}$ of purified hydroxylamine.

d. Add $3 \mathrm{~mL}$ of BPhen.

e. Add $3 \mathrm{~mL}$ of Iso-OH. 
f. Shake vigorously for 1 minute and allow the phases to separate (shown in Figure 1).

g. Drain the lower phase containing the purified sodium acetate.

5. Uranyl-sulfate solution.
a. $\mathrm{pH} 1$.
b. $140 \mathrm{~g} / \mathrm{L} \mathrm{U}$ with corrosion and fission products.

\subsection{PROCEDURE}

1. To the $2-\mathrm{mL}$ volumetric flask, add $100 \mu \mathrm{L}$ of uranylsulfate.

2. Add $100 \mu \mathrm{L}$ of hydroxylamine.

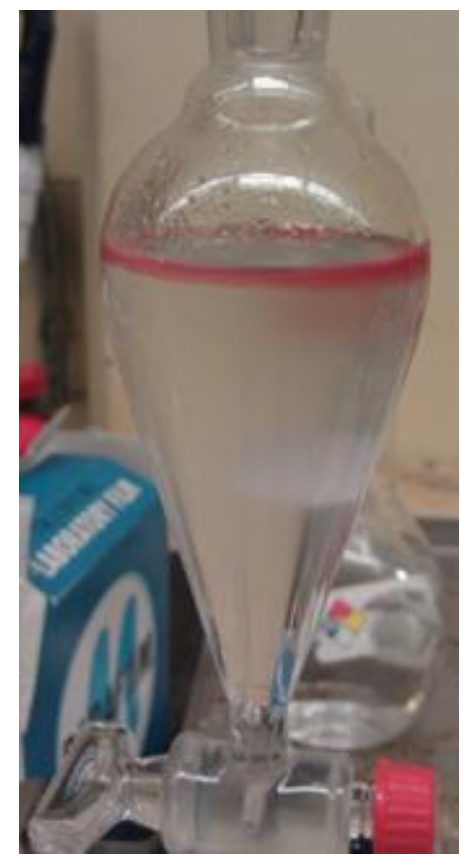

3. Add $300 \mu \mathrm{L}$ of sodium acetate.

FIGURE 1 An Extraction of $\mathrm{Fe}(\mathrm{II}) \mathrm{BPhen}$ into Iso-OH

4. Add $1000 \mu \mathrm{L}$ of BPhen.

5. Gently shake the volumetric flask to mix the BPhen.

6. The solution should change to a red-orange color.

7. Add DI water to the 2-mL mark.

8. Mix the solution using a transfer pipette and transfer the solution to a test tube. The $\mathrm{pH}$ of this solution should be approximately 6 .

9. Take $1000 \mu \mathrm{L}$ of the solution and transfer it to the second test tube.

10. Add $1000 \mu \mathrm{L}$ of Iso-OH to the second test tube.

11. Shake the second test tube rigorously for 1 minute and allow the phases to separate.

12. Prepare a cuvette containing neat Iso- $\mathrm{OH}$ for baseline measurement.

13. Separate the top alcohol phase from the second test tube to a 1-cm cuvette. This phase should be a light pink to red color. Measure the sample.

14. The absorbance at $800 \mathrm{~nm}$ should be zero or at least 0.01 . If the solution exhibits absorbance at $800 \mathrm{~nm}$, agitate the sample or change the cuvette. 
15. The concentration of iron(II) in the original uranyl-sulfate solution is given by the absorbance $(A)$ at $533 \mathrm{~nm}(\mathrm{ppm} \pm 5 \%)$ :

$$
[F e(\mathrm{II})]=\left(\frac{2000 \mu L}{100 \mu L}\right) \times(3.5 p p m) \times\left(A_{533 n m}\right)=(70 p p m) \times\left(A_{533 n m}\right)
$$

16. If the solution's absorbance saturates the detector $(\mathrm{A}>3)$, then the organic phase can be quantitatively diluted with Iso-OH. Take $500 \mu \mathrm{L}$ of the loaded phase and dilute it with $500 \mu \mathrm{L}$ of neat Iso-OH. Adjust the above equation to $140 \mathrm{ppm} \times A_{533 \mathrm{~nm}}$. 


\section{DEVELOPMENT OF THE METHOD}

\subsection{PEROXIDE DESTRUCTION} metal surface:

Hydrogen peroxide undergoes disproportionation, particularly when in contact with a

$$
\mathrm{H}_{2} \mathrm{O}_{2}(l) \rightarrow \mathrm{H}_{2} \mathrm{O}(l)+1 / 2 \mathrm{O}_{2}(g)
$$

The half reactions are as follows:

$$
\begin{aligned}
& 1 / 2 \mathrm{H}_{2} \mathrm{O}_{2}+\mathrm{H}^{+}+\mathrm{e}^{-} \rightarrow \mathrm{H}_{2} \mathrm{O} \\
& \mathrm{H}^{+}+1 / 2 \mathrm{O}_{2}+\mathrm{e}^{-} \rightarrow 1 / 2 \mathrm{H}_{2} \mathrm{O}_{2}
\end{aligned}
$$

The reduction standard potentials for equations (2) and (3) are $+1.78 \mathrm{~V}$ and $+0.70 \mathrm{~V}$, respectively (Shriver and Atkins 2006). Thus, any redox reactions with a standard potential within this region could potentially decompose $\mathrm{H}_{2} \mathrm{O}_{2}$. A candidate for $\mathrm{H}_{2} \mathrm{O}_{2}$ decomposition in solution is the $\mathrm{Fe}(\mathrm{II} / \mathrm{III})$ redox couple $\left(\mathrm{E}^{0}=+0.77 \mathrm{~V}\right)$ (Shriver and Atkins 2006). The reduction of $\mathrm{Fe}^{3+}$ by $\mathrm{H}_{2} \mathrm{O}_{2}$ is shown in the following equation:

$$
\mathrm{Fe}^{3+}+1 / 2 \mathrm{H}_{2} \mathrm{O}_{2} \rightarrow \mathrm{Fe}^{2+}+\mathrm{H}^{+}+1 / 2 \mathrm{O}_{2}
$$

The $\mathrm{E}^{0}$ for this reaction is $+0.07 \mathrm{~V}$ and thus thermodynamically favorable (Shriver and Atkins 2006). There is also the oxidation of $\mathrm{Fe}^{2+}$ :

$$
\mathrm{Fe}^{2+}+1 / 2 \mathrm{H}_{2} \mathrm{O}_{2}+\mathrm{H}^{+} \rightarrow \mathrm{Fe}^{3+}+\mathrm{H}_{2} \mathrm{O}
$$

which is also thermodynamically favorable $\left(\mathrm{E}^{0}=1.01 \mathrm{~V}\right)$.

\subsection{COLORIMETRY AND METHOD}

Both $\mathrm{Fe}(\mathrm{II})$ and $\mathrm{Fe}(\mathrm{III})$ absorb visible light with relatively strong intensities. There exist several methods of quantification that use colorimetry. Vogel's Textbook of Quantitative Chemical Analysis (Jeffery et al. 1989) reports two methods that uniquely quantify both $\mathrm{Fe}(\mathrm{II})$ and Fe(III). Quantification of Fe(III) utilizes thiocynate to give intensely red-colored compounds without interference from $\mathrm{Fe}(\mathrm{II})$. However, the presence of sulphate anions can significantly complex the Fe(III). For quantification of Fe(II), 1,10-phenanthroline (phen) complexes form a red-orange solution that exhibits a maximum absorbance at $515 \mathrm{~nm}\left(\varepsilon=11,100 \mathrm{M}^{-1} \mathrm{~cm}^{-1}\right)$. $\mathrm{Fe}(\mathrm{III})$ is also complexed by this ligand; however, its maximum absorbance is observed at $396 \mathrm{~nm}$, which directly overlaps in absorbance with U(VI). The presence of additional transition metals such as silver, bismuth, copper, nickel, and cobalt can seriously interfere with and affect the absorbance when using phen. Derivatives of this ligand have demonstrated a competitive edge for iron quantification in solution. Smith et al. (1952) and Gahler et al. (1961) reported the use of 
the ligand 4,7- Diphenyl-1,10-phenanthroline (BPhen; see Figure 2) for $\mathrm{Fe}(\mathrm{II})$ quantification in the concentration range of 0.0001 to $2 \%$. The reported extinction coefficient for $\mathrm{Fe}(\mathrm{II})$ with $\mathrm{BPhen}$ is $22,400 \mathrm{M}^{-1} \mathrm{~cm}^{-1}$ at $533 \mathrm{~nm}$. A sample containing $10 \mu \mathrm{M}$ of $\mathrm{Fe}$ (II)-BPhen would exhibit an absorbance of approximately 0.2 , which is an acceptable quantification for most spectrometers.

The procedure for iron quantification with BPhen, however, requires additional manipulations and separations. A generalized procedure follows; concentrations and volumes are omitted:

1. Prepare iron-containing solutions in a

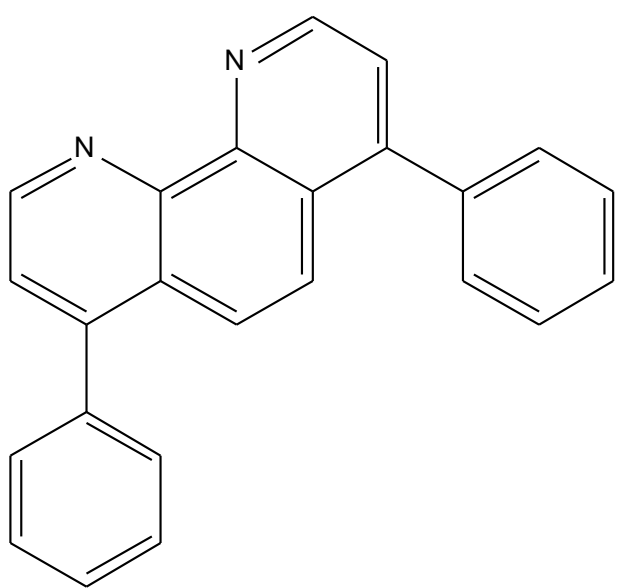

FIGURE 2 4,7-Diphenyl-1,10phenanthroline (BPhen)<smiles>CC(C)CCO</smiles>

FIGURE 3 Isoamyl Alcohol (Iso-OH)

4. Add excess BPhen.

5. Adjust $\mathrm{pH}$ of solution if necessary.

6. Contact the aqueous phase with isoamyl alcohol (Iso-OH; see Figure 3.).

7. Shake solutions and allow the phases to separate.

8. Separate the iron-containing organic phase into a cuvette.

9. Having corrected for background subtraction, measure the absorbance spectra at $533 \mathrm{~nm}$.

10. Repeat the process using standardized solutions of $\mathrm{Fe}(\mathrm{II})$ and generate a calibration curve within the concentration region of interest.

11. Introduce the appropriate contaminants and test the reliability.

\subsection{SPECIATION}

Speciation deamgrams for Fe (II), uranyl ion, and phen based on the stability constants of phen (not BPhen) with selected metals reported in the National Institute of Standards and Technology (NIST) database are shown in Figure 4 (NIST 2004). The literature concerning complexation of BPhen is limited. The stability constant for the U(VI)-phen complex was 

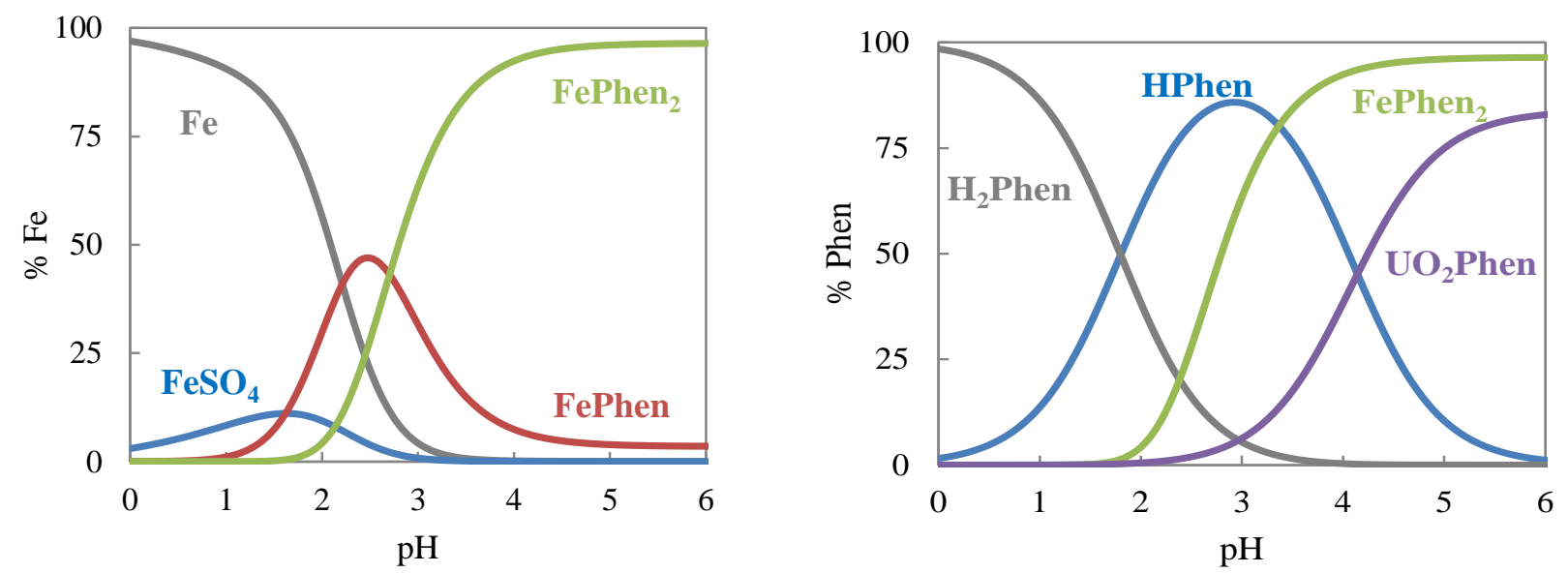

FIGURE 4 Speciation Diagram of Fe(II) and U(VI)-phenanthroline (The diagram on the left shows the species formation relative to $\mathrm{Fe}$ (II). The diagram on the right shows the speciation with respect to phenanthroline.)

substituted with that of $\mathrm{Nd}(\mathrm{III})$-phen. This assumption should be regarded with caution but was used nonetheless due to the scarce literature concerning U(VI)-phen. The diagram on the lefthand side of Figure 4 shows the speciation of iron(II) in the presence of excess BPhen and U(VI) as a function of $\mathrm{pH}$. Beyond $\mathrm{pH} 4$, the majority of the iron(II) is complexed by phen.

\subsection{CALIBRATION CURVE}

A $10 \%$ (w/w) solution of hydroxylamine (99.999\% Trace analysis, Sigma-Aldrich) and sodium acetate (Sigma-Aldrich) was prepared using milli-pore deionized water. Each solution was purified of iron contaminants as reported in Smith et al. (1952).

A solution of BPhen (>99\%, Fluka) was prepared by dissolving $19.5 \mathrm{mg}$ in $25 \mathrm{~mL}$ of ethanol and filling to volume $(50 \mathrm{~mL})$ of deionized water. A stock solution of Fe(II) was prepared by dissolving $\mathrm{Fe}\left(\mathrm{NH}_{4}\right)_{2}\left(\mathrm{SO}_{4}\right)_{2} \cdot 6 \mathrm{H}_{2} \mathrm{O}$ in dilute $\mathrm{H}_{2} \mathrm{SO}_{4}$. Iso-amyl alcohol (Sigma-Aldrich) was used without purification.

A Cary 5E UV-Vis-NIR spectrometer was used for absorption measurements. The absorption range was between 800 and $400 \mathrm{~nm}$. The incremental wavelengths were $1 \mathrm{~nm}$ and the slit width was $1 \mathrm{~nm}$. A reference solution containing hydroxylamine and sodium acetate was used. Temperatures of the solutions were in the range of $20 \pm 2^{\circ} \mathrm{C}$.

Aqueous solutions of $\mathrm{Fe}(\mathrm{II}) \mathrm{BPhen}$ were prepared in $2 \mathrm{~mL}$ volumetric flasks according to Smith et al. (1952). Upon addition of excess BPhen, a vibrant red complex appeared. The concentrations of $\mathrm{Fe}(\mathrm{II})$ in the volumetric flask were in the range of $0.7-10.4 \mathrm{ppm}$. The $\mathrm{pH}$ of the solutions was estimated to be in the range of 4-6 as measured using pHydrion paper (2-12). One milliliter of aqueous solution was contacted with $1 \mathrm{~mL}$ of Iso- $\mathrm{OH}$ and vortexed for one minute. The solutions were centrifuged and separated. The organic phase was taken for measurement. A 
calibration curve is shown in Figure 5. The concentration range of $\mathrm{Fe}(\mathrm{II})$ demonstrated a linear relationship with the absorbance at $533 \mathrm{~nm}$. From Figure 5, the Fe(II) concentration is equal to $3.5 \mathrm{ppm}$ times the absorbance at $533 \mathrm{~nm}$ (1-cm path length).

\subsection{POTENTIAL INTERFERENCES}

A solution containing uranyl-sulfate, chromium-sulfate, and a cocktail of fission products was tested for interferences in the $\mathrm{Fe}$ (II)-BPhen absorbance. The method above was tested in the presence of $0.1 \mathrm{M}$ uranyl-sulfate ( $\mathrm{pH} 1$, depleted uranium) that was diluted from a $0.6 \mathrm{M}$ uranylsulfate stock. The $\mathrm{pH}$ of the solution was adjusted to 6 . There was no visible evidence that uranium was extracted into the alcohol with no characteristic uranyl peaks at $400 \mathrm{~nm}$ (see Figure 6 for a photograph of a typical extraction experiment). It should be noted that the uranylsulfate stock solution already contained appreciable amounts of Fe(II). The method was repeated as a function of uranyl-sulfate concentration. The Fe(II) concentration exhibited a linear dependence with increasing concentrations of uranium, as seen in Figure 7. From this linearity, the initial concentration of Fe(II) present in the stock solution was calculated to be $80 \pm 3 \mathrm{ppm}$. The linear dependence plateaued above $0.06 \mathrm{M}$ uranyl-sulfate due to the low $\mathrm{pH}(<2)$ and competition for the BPhen ligand.

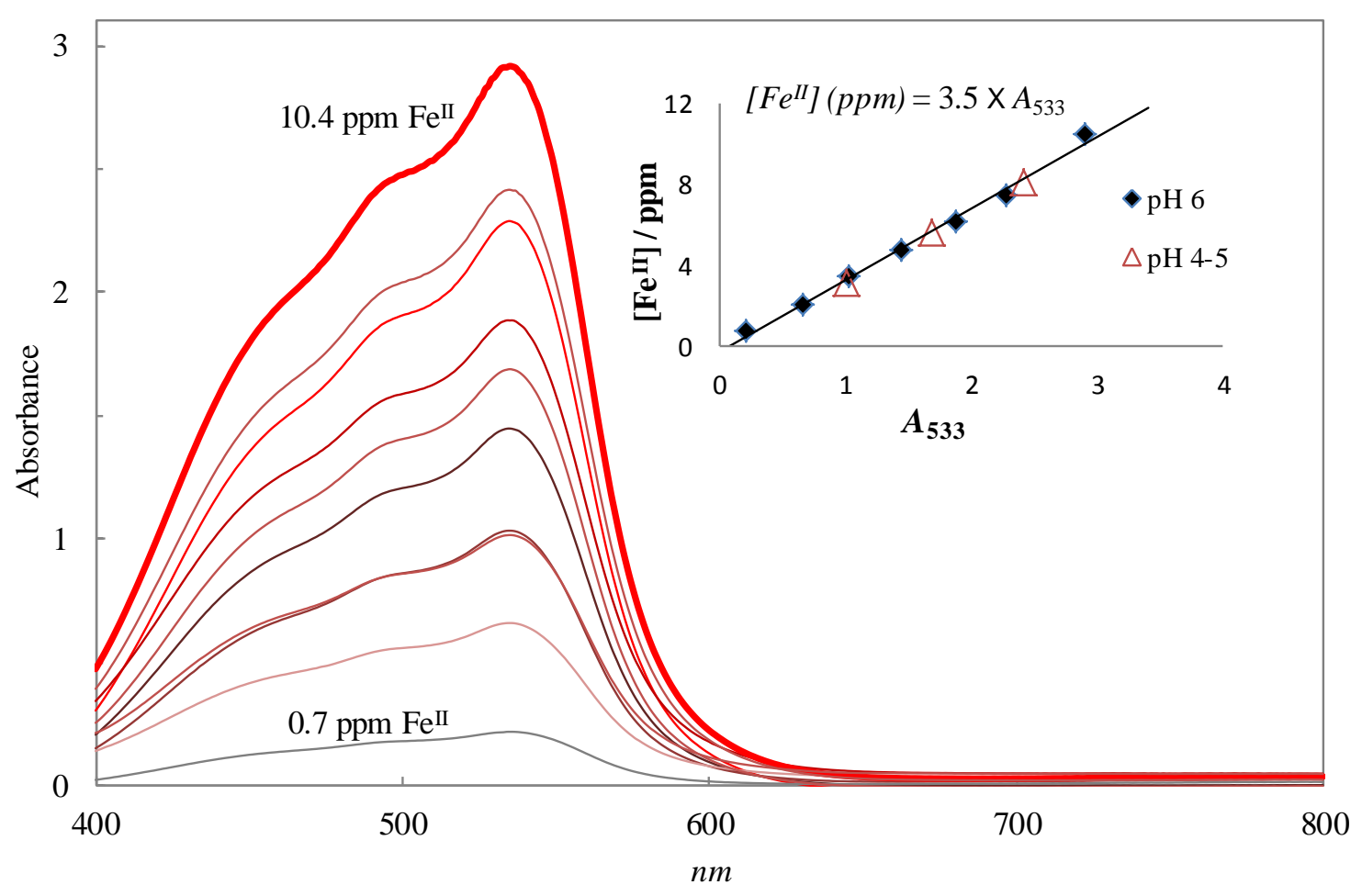

FIGURE 5 Calibration Spectra for Fe(II)-BPhen in the Range of 0.7-10.4 ppm (The insert shows the relationship between the $\mathrm{Fe}(\mathrm{II})$ concentration and the absorbance at 533 nm.) 
Chromium-sulfate was tested as a potential corrosion contaminant. Chromium (III) sulfate hydrate $\left(\mathrm{Cr}_{2}\left(\mathrm{SO}_{4}\right)_{3} \cdot \mathrm{xH}_{2} \mathrm{O}, 99.999 \%\right.$ Sigma Aldrich) was dissolved in dilute sulfuric acid. The dark-green solution was submitted for ICP-MS to determine the concentration of chromium. Five samples containing $0,9.1,21.3,33.4$, and $45.7 \mathrm{ppm} \mathrm{Cr}$ (III) were prepared in the presence of $5.8 \mathrm{ppm}$ iron-sulfate standard. The $\mathrm{pH}$ was adjusted to 6 using $\mathrm{NH}_{4} \mathrm{OH}$. The solutions containing 9.1-33.4 ppm $\mathrm{Cr}$ (III) did not interfere. However, solutions containing 45.7 ppm (nearly 8 times the concentration of iron) decreased the absorbance at $533 \mathrm{~nm}$ as shown in Figure 8. The effective cationic charges for the $\mathrm{Cr}$ (III) and $\mathrm{Fe}$ (II) ions are 4.8 and 3.1, respectively (Shannon 1976). From these values, we anticipate the stability constant for the $\mathrm{Cr}$ (III)-BPhen complex to be significant and competitive with Fe(II), although steric dependency may affect this. The stability constant for the $\mathrm{Cr}(\mathrm{III})$-phen complex is not reported in the NIST database (NIST 2004). There was no evidence that this complex was extracted into the alcohol solvent. It should be mentioned that the presence of $\mathrm{Cr}$ (III) in solution would likely indicate an excess of iron due to stainless-steel corrosion.

The method was tested in the presence of a surrogate PUREX raffinate solution. This cocktail contained the rare-earth elements and

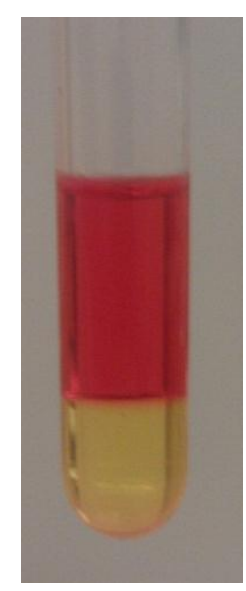

FIGURE 6 The Two-Phase Extraction of Fe(II)-BPhen (top red layer) from a Solution of UranylSulfate (bottom yellow layer) selected transition metal fission products dissolved in $3 \mathrm{M} \mathrm{HNO}_{3}$. The solution was dark brown and the concentrations were determined by inductively coupled plasma mass spectrometry (ICPMS). The final concentrations after dilution are listed in Figure 9. An aliquot was diluted and tested in the presence of $5 \mathrm{ppm}$ Fe(II) sulfate standard. The $\mathrm{pH}$ of the solution was adjusted to 6 using $\mathrm{NH}_{4} \mathrm{OH}$. The absorbance at $533 \mathrm{~nm}$ was not affected, as shown in Figure 9.

The literature suggests that other metal ions may interfere, but many of these elements are not anticipated through uranium fission. $\mathrm{Cu}$ (II) and $\mathrm{Co}(\mathrm{II})$ may interfere, according to Smith et al. (1952). The stability constants for these divalent cations with BPhen are orders of magnitude higher than Fe(II) (Irving and Mellor 1962). However, Smith et al. (1952) reported that these cations can be separated from $\mathrm{Fe}(\mathrm{II})$-BPhen during the extraction if the $\mathrm{pH}$ of the aqueous solution is adjusted to more acidic conditions $(4 \leq \mathrm{pH}<6)$. Gahler et al. (1961) used a similar method to the one reported here and demonstrated that $\mathrm{V}(\mathrm{V}), \mathrm{Mn}(\mathrm{II})$, and $\mathrm{Ni}(\mathrm{II})$ interfered. This is contrary to Smith et al. (1952), whose method more closely reflects our method. Trace amounts of $\mathrm{Ni}$ (II) are to be expected with corrosion of 316 stainless steel but should be overwhelmed by the more abundant Fe(II) concentration in the steel. Tellurates will be reduced to the metallic form by hydroxylamine but should not be extracted into the alcohol solvent and are expected to be present in $<1$ ppm quantities. 


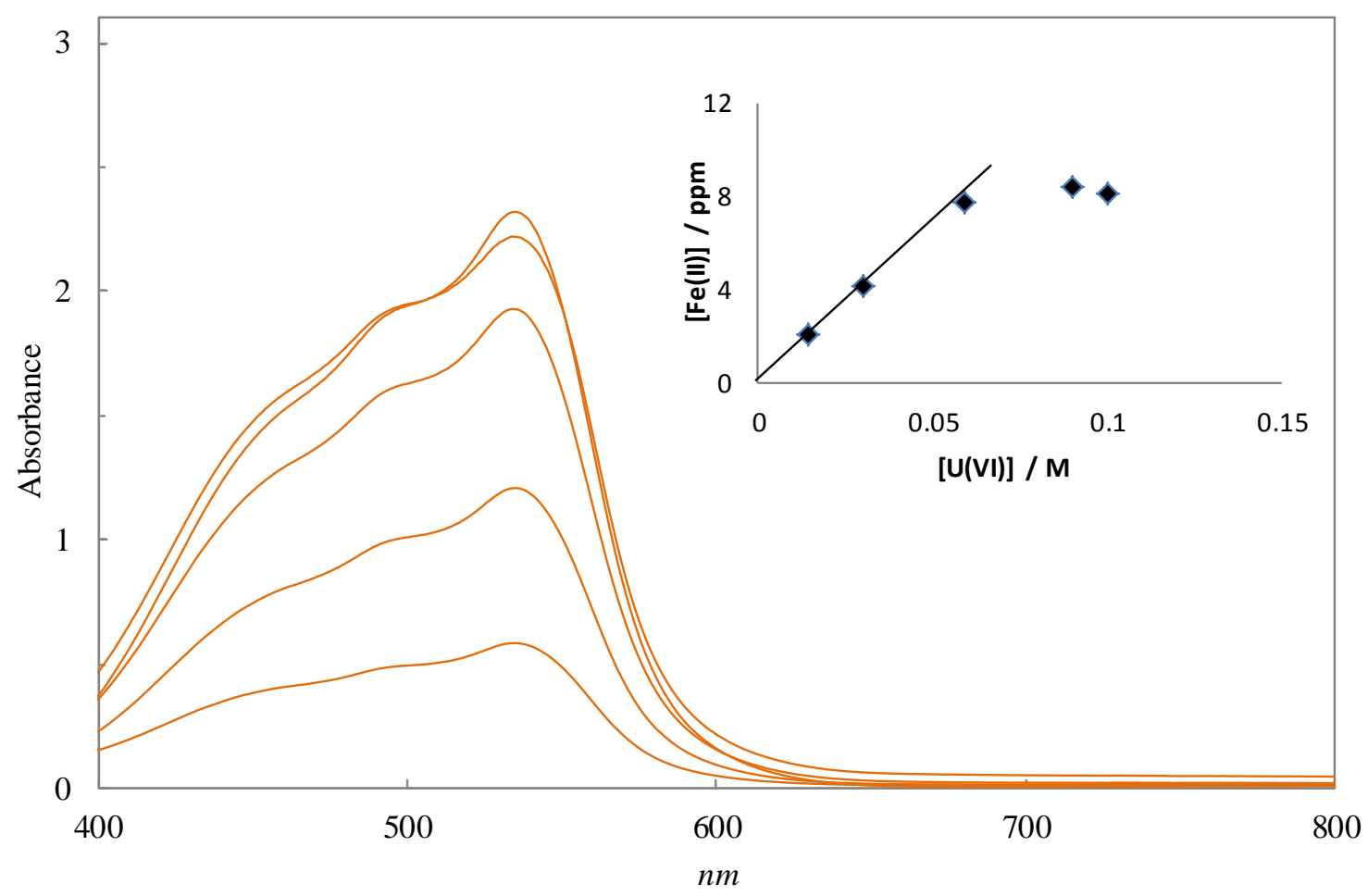

FIGURE 7 The Absorbance of Fe(II)-BPhen in the 0.6 M Uranyl-Sulfate Stock Solution (The concentration of uranyl-sulfate was tested in the range of 0.01-0.1 M. From the linear trendline in the insert, the concentration of $\mathrm{Fe}$ (II) in the uranyl-sulfate stock solution was determined to be $80 \pm 3 \mathrm{ppm}$. At high concentrations of uranyl-sulfate, the spectrometer was saturated with $\mathrm{Fe}$ (II) and unusable. U(VI)-BPhen complexes were not extracted.) 


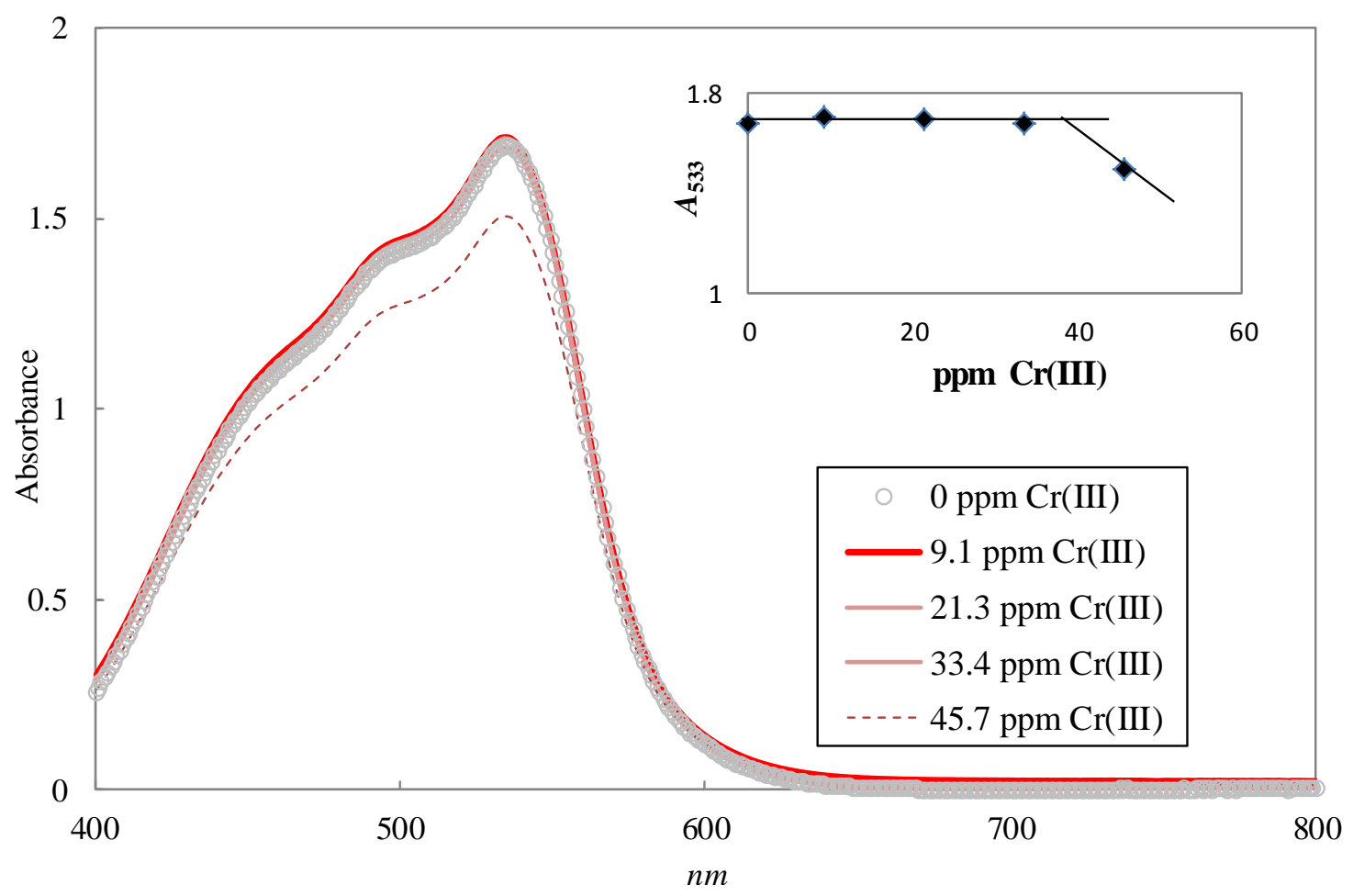

FIGURE 8 The Absorbance of 5 ppm Fe(II)-BPhen in the Presence of $\mathrm{Cr}$ (III) (At 45.7 ppm $\mathrm{Cr}$ (III) there was significant interference. $\mathrm{Cr}$ (III)-Bphen complexes were not extracted into the alcohol.)

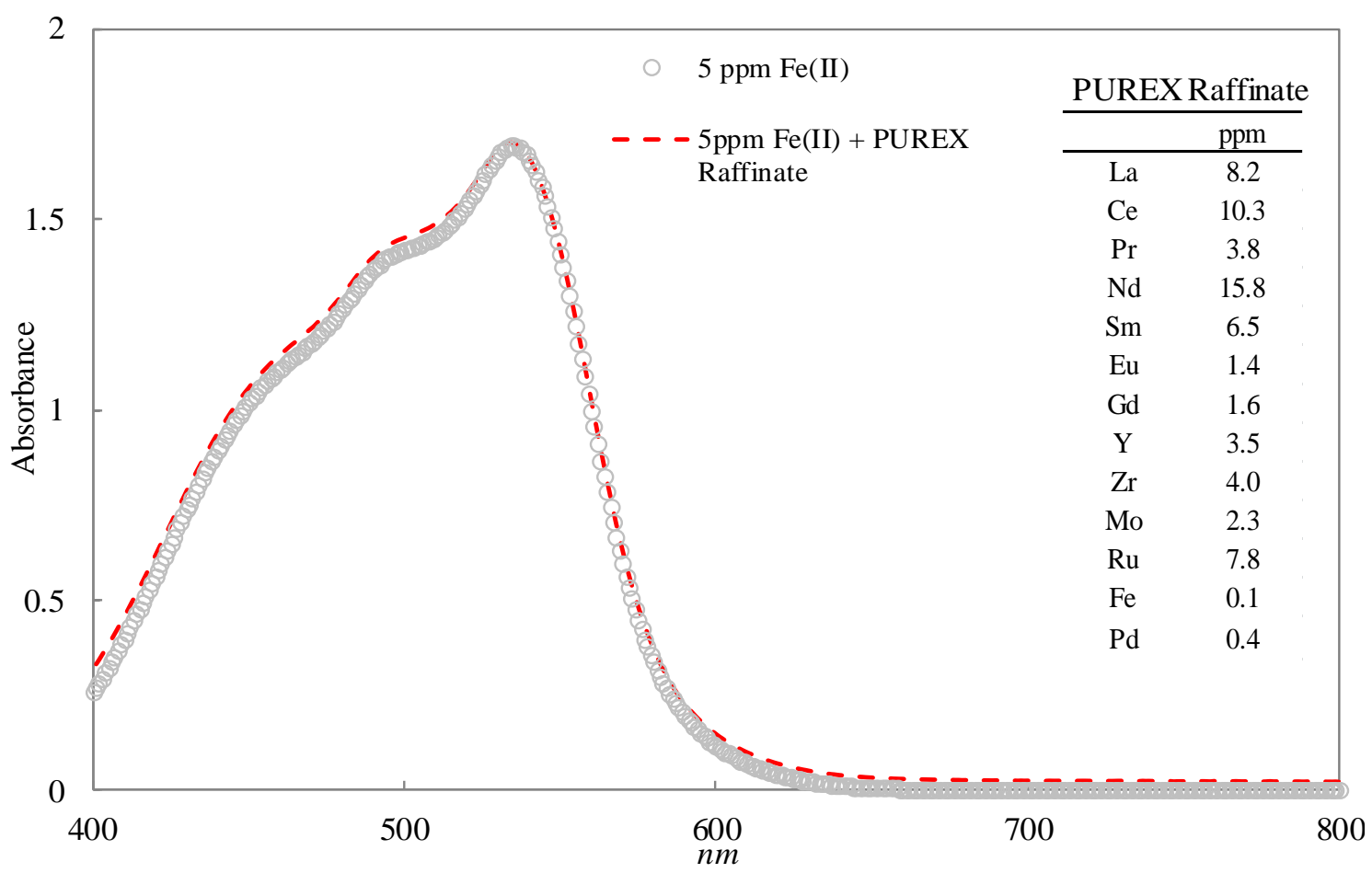

FIGURE 9 The Absorbance of 5 ppm Fe(II)-BPhen in the Presence of a PUREX Raffinate 


\section{REFERENCES}

Gahler, A.R., R.M. Hamner, and R.C. Shubert, 1961, "Spectrophotometric determination of traces of iron with 4,7-diphenyl-1,10-phenanthroline. Application to vanadium, chromium, titanium, niobium, tantalum, uranium, tungsten metals, alloys, and compounds," Analytical Chemistry 33:1937-1941.

Irving, H., and D.H. Mellor, 1962, "The stability of metal complexes of 1,10-phenanthroline and its analogues. Part I. 1,10-Phenanthroline and 2,2'-bipyridyl," Journal of the Chemical Society 5222-5237.

Jeffery, G.H., J. Bassett, J. Mendham, and R.C. Denney (eds.), 1989, Vogel's Textbook of Quantitative Chemical Analysis, $5^{\text {th }}$ ed. Longman Scientific Technical, John Wiley \& Sons, Inc. New York, NY, pp. 691.

NIST (National Institute of Standards and Technology), 2004, NIST Standard Reference Database 46; NIST Critically Selected Stability Constants of Metal Complexes Database, version 8.0, U.S. Department of Commerce, Washington, DC.

Shannon, R.D., 1976, "Revised effective ionic radii and systematic studies of interatomic distances in halides and chalcogenides," Acta Crystallographica A32:751-767.

Shriver, D.F., and T.L. Atkins, 2006, Inorganic Chemistry, $4^{\text {th }}$ ed., W.H. Freeman \& Company, New York, NY, pp. 383.

Smith, G.F., W.H. McCurdy, and H. Diehl, 1952, "The colorimetric determination of iron in raw and treated municipal water supplies by use of 4:7-diphenyl-1:10-phenanthroline," Analyst 77:418-422. 
This page intentionally left blank 



\section{Argonne}

Chemical Science and Engineering Division

Argonne National Laboratory

9700 South Cass Avenue, Bldg. 205

Argonne, IL 60439-4837

www.anl.gov 